\title{
Laboreal
}

Volume $2 \mathrm{~N}^{\circ} 2$ | 2006

Varia

\section{Mudanças organizacionais, saúde e bem-estar na banca portuguesa : idade e sentidos do trabalho numa nova relação salarial}

Cambios organizacionales, salud y bienestar en la banca portuguesa : edad y sentidos del trabajo en una nueva relación salarial

Changements organisationnels, santé et bienêtre dans la banque portugaise : âge et sens du travail dans une nouvelle relation salariale

Organizational changes, health and well-being in the banking sector in

Portugal : age and meanings of work in a new value system

\section{Isabel Torres}

\section{OpenEdition}

\section{Journals}

Edição electrónica

URL: http://journals.openedition.org/laboreal/13382

DOI: $10.4000 /$ laboreal. 13382

ISSN: 1646-5237

Editora

Universidade do Porto

Refêrencia eletrónica

Isabel Torres, « Mudanças organizacionais, saúde e bem-estar na banca portuguesa : idade e sentidos do trabalho numa nova relação salarial », Laboreal [Online], Volume $2 N^{0} 2 \mid 2006$, posto online no dia 01 dezembro 2006, consultado o 24 setembro 2020. URL : http://journals.openedition.org/laboreal/ 13382 ; DOI : https://doi.org/10.4000/laboreal.13382

Este documento foi criado de forma automática no dia 24 setembro 2020.

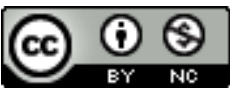

Laboreal está licenciado com uma Licença Creative Commons - Atribuição-NãoComercial 4.0 Internacional. 


\section{Mudanças organizacionais, saúde e bem-estar na banca portuguesa : idade e sentidos do trabalho numa nova relação salarial}

Cambios organizacionales, salud y bienestar en la banca portuguesa : edad y sentidos del trabajo en una nueva relación salarial Changements organisationnels, santé et bienêtre dans la banque portugaise : âge et sens du travail dans une nouvelle relation salariale

Organizational changes, health and well-being in the banking sector in Portugal : age and meanings of work in a new value system

Isabel Torres

\section{REFERÊNCIA}

Torres-Oliveira, M. I. (2005). Mudanças Organizacionais, saúde e bem-estar na banca portuguesa. Idade e sentidos do trabalho numa nova relação salarial. Tese de doutoramento. Faculdade de Psicologia e de Ciências da Educação da Universidade do Porto, Porto.

\section{NOTA DO EDITOR}

Manuscrito recebido em : Outubro/2006

Aceite após peritagem em : Dezembro/2006 


\section{Enquadramento}

1 A conquista de um regime democrático e a entrada na União Europeia constituíram dois marcos basilares na transformação de Portugal. Embora esta última se tenha afirmado de forma diferencial em vários quadrantes económicos e sociais, a totalidade dos sectores foi compelida a proceder a mudanças, procurando fazer face aos imperativos concorrenciais de um mercado aberto, liberalizado e desregulamentado. A banca não foi excepção. Sendo um dos sectores de maior valor estratégico e habitualmente posicionado na crista do vanguardismo, precocemente pôs em marcha sucessivos planos de mudança, dando a conhecer, de forma inequívoca, a força dos valores mercantis no e do trabalho. O domínio destes sobre outros valores - os não dimensionados (Schwartz, 2000) - é reveladora das opções que marcam o início de um novo ciclo, para o qual muito contribuiu a afirmação de novas instituições de crédito, capazes de conferir à organização do trabalho e à relação salarial um novo figurino. Estas mudanças são justificadas pela necessidade de conferir competitividade às instituições, de as tornar flexíveis, objectivos estes passíveis de serem atingidos por via de uma política de concentração, de redução de efectivos, de aposta em novas tecnologias da informação e da comunicação, de multiplicação de produtos e de serviços, de uma nova abordagem ao cliente, entre outros. É principalmente com base em argumentos ligados à satisfação da clientela, que se justificam as novas opções em matéria de gestão da mão-de-obra.

2 Sem julgar o grau de adequação das mudanças implementadas no sector, emerge a necessidade de reflectir sobre as suas implicações ao nível da actividade de trabalho e sobre aqueles que a desenvolvem.

\section{Compreender as relações entre o trabalho, a saúde e o bem-estar dos bancários em Portugal}

3 No trabalho que aqui apresentamos propusemo-nos caracterizar as principais mudanças vividas pelos bancários, entre 1996 e 2002, através das percepções evidenciadas por diversos actores, directa ou indirectamente, envolvidos com as transformações da banca. Foi nosso objectivo compreender a forma como os bancários percepcionaram e viveram essas mudanças e avaliar em que medida estava posta em causa a preservação de si e da sua saúde no trabalho. Orientamos também o nosso olhar para os sentidos que vão sendo atribuídos à vida no trabalho, considerando os factores que mais contribuem para a emergência de estimulação positiva e de stress negativo e que se prendem com as vivências de prazer e de sofrimento no trabalho. Em termos metodológicos privilegiamos a conjugação das abordagens quantitativa e qualitativa, defendida por diversos autores que se propõem estudar as relações entre trabalho e saúde, perseguindo maior diversidade das fontes de informação.

4 Do ponto de vista das técnicas: administramos um questionário (adaptado dos instrumentos usados no Projecto Flexihealth (Vandenberghe, De Zanet, De Keyser, Hansez, \& Grisard, 2004) a quinhentos e três bancários; realizamos entrevistas individuais com bancários, com profissionais que prestam serviços de assistência médica, psicológica e social aos bancários, com sindicalistas e com profissionais pertencente à APB Associação Portuguesa de Bancos e ao então IDICT Instituto para o 
Desenvolvimento e Inspecção das Condições de Trabalho ; foram ainda desenvolvidas duas sessões colectivas com bancários, ao abrigo da metodologia de Ferreira (1993), designada de análise colectiva do trabalho.

\section{Diferentes condições, diversas actividades bancárias}

5 Os resultados da nossa pesquisa evidenciaram a existência de novas opções da banca após as mudanças implementadas, em matéria de gestão dos seus recursos humanos, dando conta da presença de diversas actividades no contexto em estudo, desenvolvidas sob diferentes condições. Algumas variáveis parecem ser determinantes para estas opções, entre as quais salientamos a idade e a relação com a clientela.

6 De um modo geral, o contacto regular com o público parece ser assegurado, predominantemente, pelos bancários com menos de trinta e cinco anos, tendencialmente do sexo masculino, com níveis académicos mais elevados e com reduzidas responsabilidades por dependentes. São estes os que mais reconhecem beneficiar de situações propícias à formação e ao desenvolvimento, realizarem mais trabalho suplementar, trabalho esse menos pago, os que mais afirmam ter sido sujeitos a mudanças, não apenas em quantidade, mas em diversidade. Concretamente, estes inquiridos revelam ter-se confrontado com mais mudanças de ritmo, de horários, de chefias e de colegas e ainda com mais aumentos da carga de trabalho, apesar de afirmarem desejar mudar de tarefas e reduzir a sua carga de trabalho. Finalmente os que mais contactam com os clientes são os que mais afirmam que as mudanças de tarefas, de ritmo, de superior e de local, assim como os aumentos da carga de trabalho, foram causadoras de stress negativo.

7 Procuramos também compreender os motivos que conduzem os bancários a realizar trabalho suplementar. Para além dos participantes considerarem tratar-se de uma imposição superior, o prolongamento dos tempos efectivos de trabalho é justificado pelo receio de defraudar expectativas (do banco e da chefia) e ainda devido às exigências que a actividade coloca, visando o cumprimento do prescrito.

8 Pesquisamos ainda as principais fontes de prazer e de desprazer no trabalho reconhecidas pelos bancários. Os discursos da maioria dos participantes orientam-se para o desprazer que esta actividade faz sentir ; as principais razões parecem variar em função da idade do bancário. Os participantes abordam o desprazer que muitos dos jovens bancários sentem pelo facto das responsabilidades que lhes são conferidas se mostrarem desajustadas e aquém das suas qualificações académicas, muitas das vezes com implicações imediatas sobre a vivência de monotonia no trabalho; são também os mais jovens que parecem estar mais sujeitos a um sentimento de insegurança no trabalho, pela precariedade que associam à sua relação laboral ; por seu lado, é patente que os que possuem mais de quarenta anos, vivem sobressaltados com a ideia de lhes ser retirada a possibilidade de participarem activamente na dinâmica organizacional e de lhes ser imposta uma reforma antecipada, impedindo-os de exercer o seu direito ao trabalho, em idade activa. Como síntese, podemos dizer que os níveis de stress negativo que apuramos parecem explicar-se pela evolução mais desfavorável das condições de trabalho nos últimos anos e de um baixo nível de estimulação positiva. Finalmente, 
níveis menos elevados de estimulação positiva parecem encontrar-se com menores oportunidades de formação e de desenvolvimento.

\section{Proposta para uma nova compreensão das relações entre o controlo e o stress na banca}

9 Alguns resultados dos tratamentos estatísticos dos dados recolhidos pelo questionário levantaram questões de natureza teórico-metodológica, levando-nos, concretamente, ao questionamento do modelo comportamental e do conceito de trabalhador (Lacomblez, 1986) subjacentes à abordagem transaccional do stress, que sustentou a opção pelo questionário que acabámos por utilizar. Aqui, a valência qualitativa da nossa pesquisa revelou-se de particular importância, por permitir uma melhor ancoragem no real da vivência dos trabalhadores da banca. Podemos assim confirmar o quanto as entrevistas e as sessões colectivas contribuíram para encontrar novos sentidos na interpretação dos primeiros resultados e abriram portas para o principal contributo teórico desta tese.

10 O modelo transaccional do stress tem, subjacente, uma concepção específica de ser humano no trabalho, sendo o seu enfoque particularmente centrado nas dimensões adaptativas empreendidas pelo sujeito, quando se confronta com uma situação ameaçadora, pelo que é atribuída grande importância ao conceito de regulação interna e ao conceito de coping. Afigura-se-nos assim uma visão do homem cujo campo de intervenção é singularmente restrito, desvalorizando o seu papel na construção e reconstrução de significados face às transacções que vai estabelecendo, no seio de um determinado colectivo. Parece-nos ser ainda afastada deste modelo a reflexão em torno da acção do sujeito sobre a optimização da sua saúde de uma forma mais alargada.

11 Mas uma dimensão especialmente cara nesta investigação prendeu-se com o estudo das relações entre a percepção de controlo sobre o trabalho e os indicadores de stress negativo (distress) e de stress positivo (eustress). Com base no modelo transaccional, estimar-se-ia que a relação entre estas duas variáveis teria de ser de sinal contrário isto é : quanto mais forte for a percepção de controlo das diversas dimensões do trabalho, é esperado que o nível de stress negativo seja menor. Ora os nossos dados evidenciaram resultados contraditórios com este postulado. Assim, se os bancários que mais contactam com os clientes (em geral mais jovens) revelam um maior nível de stress negativo, os mesmos deixam transparecer um maior controlo sobre o seu trabalho ; por outro lado, os menos jovens evidenciam, pelas suas respostas ao questionário, um nível de stress negativo igualmente importante (quando o que está em causa é o stress negativo, não se verificam diferenças significativas entre inquiridos pertencentes a diferentes escalões etários) associado, contudo, a níveis mais baixos de controlo sobre o trabalho.

$12 \mathrm{Na}$ verdade, é o próprio conceito de controlo, tal como entendido no modelo transaccional, que está em jogo : trata-se aqui da percepção de poder dominar, apesar dos condicionalismos, as várias dimensões do trabalho, baseando-se na "evidência" de um ser humano que, num espaço de acção circunscrito por outros, busca desafios e se mostra competitivo, capaz de aceitar responsabilidades acrescidas, ainda que em conflito, conseguindo gerir os diversos constrangimentos temporais e ainda de se projectar favoravelmente no futuro. O postulado é que este indivíduo será menos atingido por stress negativo. E é esta capacidade de dominar um micro-mundo de um 
trabalho predefinido que permitirá distinguir os mais "vulneráveis", incapazes de desenvolverem estratégias adaptativas eficazes, pelo que precisam de ser apoiados, reconvertidos ou, talvez até, afastados do modelo de produção dominante.

De facto, a nossa pesquisa acabou por questionar, pelo menos, a possibilidade das relações previstas por este modelo controlo elevado e stress negativo serem visíveis de forma transversal em todos os contextos.

Não deixa de ser interessante realçar que encontramos proximidades entre esta concepção de ser humano subjacente ao modelo transaccional do stress e aquela que parece ser considerada por alguns dos que assumem a direcção bancária. Os perfis de recrutamento e de gestão de carreiras valorizam efectivamente níveis académicos mais elevados, alta capacidade de trabalho e de adaptação às múltiplas mudanças e às novas tecnologias, rapidez e qualidade de trabalho, inquestionável disponibilidade, "agressividade comercial", ambição profissional e adesão facilitada aos novos valores no trabalho - o que contribui para explicar a preferência constatada pelos mais jovens, susceptíveis de manterem um relativo equilíbrio e um bom padrão de desempenho, num contexto que é entendido como instável, complexo e ambíguo.

15 As expectativas depositadas nos bancários mais jovens, fazem com que a organização do trabalho na banca lhes promova o contacto com um trabalho mais "exigente", que envolve mais desafios, a perseguição de objectivos crescentes, uma maior e mais regular proximidade ao cliente, a prática de tempos de trabalho mais longos e níveis superiores e individualizados de responsabilização. Tendo os jovens ingressado numa banca em mudança, a adesão aos seus novos valores torna-se evidente porque imposta a partir das referidas expectativas e coerente com a ambição de quem começa, num ambiente francamente competitivo, favorecendo-lhes a percepção de um maior domínio sobre o trabalho.

16 Todavia, é, na verdade, a concepção do "controlo sobre o trabalho" que está aqui em questão, já que certos dados desta pesquisa levam-nos a concluir que essas exigências e níveis de responsabilização não se fazem acompanhar por uma maior participação ao nível da concepção do trabalho - o que contribui para explicar como um maior controlo aparente pode ser associado a stress negativo. Falamos assim de um efeito de responsabilidades confiadas sem responsabilidade efectiva, salientado por Clot, Rochex e Schwartz (1995, p. 210, tradução livre).

17 Consideramos que é justamente o desencontro entre expectativas e exigências criadas, finalmente, face a si mesmo (para as quais concorrem as expectativas e exigências preconizadas também pelo próprio colectivo) e as suas condições de trabalho, nomeadamente as que implicam constrangimentos e conflitos múltiplos, que pode ser gerador de vivência de stress negativo. É o peso do colectivo e o peso de "si próprio" que impedem o mais jovem de falhar, de mostrar "fragilidades", que o poderão afastar de uma oportunidade profissional a salvaguardar. É aqui que o medo poderá, paradoxalmente, assumir um papel verdadeiramente funcional, na medida em que ajuda o sujeito a manter-se atento, "actor e espectador" de si mesmo, evitando dar sinais de desajustamento, sinais de "fora de norma", razão pela qual se avalia e reavalia sistematicamente no confronto com a acção.

Quanto aos "menos jovens", os dados remetem-nos para a desvalorização, para a falta de reconhecimento destes por parte da organização do trabalho. $O$ afastamento de tarefas "mais" exigentes, a atribuição de um trabalho com menores responsabilidades comerciais, resultam numa fraca visibilidade social, claramente penosa, não apenas 
porque é vivida "hoje", mas também porque se projecta no "amanhã", ignorando o "ontem". Por isso o stress negativo é elevado e o nível de controlo é baixo, embora se trate de bancários experientes e cientes das evoluções das empresas que integram.

\section{Uma conjuntura desfavorável}

19 A continuidade da aposta da banca em valores globalmente mercantilistas, a prevalência de uma visão solipsista (Cru, 1997, 10) do homem no trabalho, a desvalorização dos saberes experienciais e a demolição dos colectivos, são alguns dos factores que fazem da banca um espaço com reduzidas margens de manobra para a gestão da actividade e para a preservação da saúde. trabalho, essencialmente limitada à transposição das Directivas-Quadro, onde o
domínio dos riscos psicossociais permanece num estado embrionário. Paralelamente, a crise vivida pelo sindicalismo (Cru, 1997) e a sua incapacidade para apresentar soluções de peso contra a "pressão", a "desumanização" e a "precarização" que tanto preenchem os discursos dos seus dirigentes. Por seu lado, os que assumem posições ao nível da saúde ocupacional. Que responsabilidades na conivência e sustentação de um sistema que fragiliza a saúde e que dificulta a sua preservação?

Finalmente, limitados no seu poder de agir, que futuro para os que, pela adesão ou pelo silêncio face a estes valores, permanecem ligados a esta actividade?

\section{BIBLIOGRAFIA}

Clot, Y., Rochex, J.-Y. \& Schwartz, Y. (1995). L'activité et la subjectivité comme interfaces. In A.-F. Molinié (Ed.), Travail et santé mentale (pp. 203-210). Éditions ANACT.

Cru, D. (1997). Valoriser les savoirs collectifs. Entretien avec Damien Cru [versão electrónica]. Retirado em Agosto, 8, 2005de http://www. fastnet.ch/PAGE2/p2_trv_cru.html.

Ferreira, L.L. (1993). Análise colectiva do trabalho. Revista Brasileira de Saúde Ocupacional, 21, 78, 7-19.

Ferreira, L.L. (1998, Outubro). Análise colectiva do trabalho : o trabalho no centro do debate. Comunicação apresentada no $2^{\circ}$ Congresso Nacional de Saúde Ocupacional, Póvoa de Varzim, Portugal, 149164.

Ferreira, L.L. (2001, Abril). Análise colectiva do trabalho : o papel dos sindicatos numa démarche de pesquisa. Comunicação apresentada no Séminaire International Analyses du Travail et Formation, Laboratoire d'Ergonomie CNAM, Paris, França.

Lacomblez, M. (1986). L'analyse des motivations de l'homme au travail : archéologie d'un paradigme dominant. (Le travail en Sociologie). Critique Régionale, 14, 91-128. 
Schwartz, Y. (2000). Le paradigme ergologique ou un métier de philosophe. Toulouse : Octarès Éditions.

Vandenberghe, C., De Zanet, F., De Keyser, V., Hansez, I. \& Grisard, A (2004). Changements organisationnels, stress des employés et satisfaction des clients. Émergence du concept de Flexihealth. Document technique.

\section{AUTOR}

\section{ISABEL TORRES}

Universidade Lusíada do Porto e Centro de Psicologia da Universidade do Porto Rua Dr. Lopo de Carvalho, 4369-006 Porto Portugal

isabeltorres@por.ulusiada.pt 